\title{
Influence of Heavy and Low Television Watching on Study Habits of Secondary School Students-A Study
}

\author{
Syed Noor-Ul-Amin Dr. Mohammad Iqbal Mattoo
}

\begin{abstract}
The study was undertaken to find out the influence of heavy and low TV watching on study habits of secondary school students. A sample of 500 students was drawn randomly from various Government secondary and higher secondary schools of District Srinagar (J\&K). Heavy and low TV viewers were identified on the basis of Q3 and Q1. Besides, Study Habits Inventory by M.N Palsane and Anuradha Sharma was administered to assess the study habits. The collected data was analyzed by using Mean, Standard Deviation and ' $t$ ' test. Line graph was plotted in order to make the results transparent. The results revealed a significant difference between the mean scores of heavy and low TV viewers on study habits.
\end{abstract}

Key Words: Heavy and Low TV; Watching; Study Habits; Secondary School Students

\section{Introduction:}

Television is considered as an electronic carpet which seems to transport millions of persons each day to far off places. (Syed, 2010). It is relatively a new medium that has made its impression on every aspect of mundane life. It is bouncing its signal on space satellites and uses oceanic cables to transmit live telecast to its beneficiaries. This electronic medium ensures its visibility without any global discrimination. It is reported that television made its visibility some more than sixty years ago. People were not only skeptical about it, but were also jealous, unkind and even hostile. Over a short span of time, however, it emerged as a remarkable medium of communication, entertainment and education. It needs to be mentioned that it found its space in all countries of the world and has transformed our planet into a 'gigantic electronic village' bringing various people and continents close (Bushan, 1992). Over the years it became a central dimension of our everyday activity and in our country it has grown at a phenomenal pace. In India, television was introduced 25 years after its invention and 30 years after its inception through Government efforts to introduce public service broadcasting. The idea was primarily education and access to rural population. Today, average Indian home has cable and satellite access and the viewer gets information from local, national and global networks. The sheer number of channels gives him options of multiple natures. It is a powerful medium with extraordinary reach. No one can doubt its potential as a catalyst of social change. Even the perforation of cable and satellite television channels has penetrated in all corners of the country cutting across demographic and geographic barriers.

It is generally believed that television has become a very powerful medium and its contact, no doubt, can change the likes and dislikes, learning and social habits. In recent years increased attention has been focused by many professionals with regard to its impact on human lives at any stage of development. Television is considered to be potentially strong agent for children, adolescents and other family members, especially with its combined effects of audio and visual. The impact is more on adolescents because they are more impressionable than adults. Adolescence is a period during which teenagers feel the pressure of constructing an adult identity. One way of dealing with this pressure is to assemble a set of aspirations for the future. Young viewers watch television as a way of wishful identification and therefore, prefer television portrayals Boehnke, Munch, and Hoffman, (2002). It is now readily apparent that television can have a profound impact on children as well as on adolescent's development and behaviour. Television programmes are used to assist children and adolescents in various subject areas and are used along with other teaching materials, to give a well rounded approach to learning materials. This has proved successful as children prefer learning visually at a young age. Studies on various dimensions of television watching and its impact have been carried out by a host of investigators. Moderate amount of television viewing seems to be beneficial for reading. Besides, programmes to promote literacy in young children have been found with positive impact on specific early literacy skills (Moses, 2008). Higher frequency television viewing is associated with attention problems and hyper-activity in pre-school children Miller, (2007). Television viewing is believed to effect adolescents' judgments, romantic relationship and sexuality. The first and most obvious reason for this is the frequent references on television to dating, romance and sex Eggerment \& Steven (2006). Television programming may be used as a tool in the construction of 
aspirations. Positive television viewing seems to be in agreement to enhance reading and comprehension skills among younger children with higher grades (Boehnke, et al., 2002; Anderson, et.al. 2001; Razel and Broek 2001). Studies report that continuous watching of television amounts to low performance in school subjects (Caldas, and Bankston,1999). Trivedi (1991) revealed the TV viewing influence the children as well as adults. This study includes general viewing habits, social relations and some associated problems like mutual interaction and talks. Kubey and Csikszentmihaly (1990) have reported that television viewing seems to be a passive activity and that it required little concentration on their part as compared to a variety of other leisure time activities. Television viewing seems to have maintained its dominant position in today's youth leisure time. Although the introduction of computers and the internet seems to have drastically altered home access to media entertainment, still television continues to persuade children to devote substantial portions of their time to its programming (Roberts, 2000 and Koolstra, 1999). William (1986) and Gunther (1955) have revealed that televised programmes hardly affect the attitude of children. Teenagers are reported develop specific identityrelated preferences and seek opportunities to watch television in a private context (Arnett, 1995). Parker (1961) has established that television has considerably reduced the time to be spent for other activities. Besides, results have shown that television correspondingly reduces the interests in reading newspaper/s and magazine/s. The review reveals that a plethora of investigations has been carried out on children and a few studies are reported to have been carried out on adolescents to see which type of programmes they intend to watch and through which programmes they get influenced. What sort of impressions is carried out by these adolescents during viewing television? What are the preferences of children about television programmes? What types of programmes are mostly liked by these children at this stage of development? Besides, which study habits these children adopt and how they prepare for their studies \& examination? These questions motivated the investigators to peep into the existing scenario of children's television watching. It is against this background that the present investigators feels that there is a need to conduct a study on adolescents to see the influence of television viewing on their study habits with following objectives.

\section{Objectives}

The following objectives have been formulated for the present investigation.

1. To identify heavy and low television viewers,

2. To find and compare the study habits of heavy and low television viewers, and

3. To find and compare the study habits of heavy and low television viewer's on the basis of gender.

\section{Hypotheses}

1. There will be a significant difference between the mean scores of heavy and low television viewers in their study habits and.

2. Gender does not make any difference in the study habits of heavy and low television viewers.

\section{Methodology and Procedure:}

Sample

The present study was conducted on a sample of 500 students drawn randomly from various Government secondary and higher secondary schools of District Srinagar (J\&K). It needs to be mentioned that these subjects were reading in grade $10^{\text {th }}$ with an age range of $15-17$.

Tools:

The following tools have been used to collect the data.

1. Study Habit Inventory by Palsane and Anuradha Sharma: This inventory assesses eight areas of study habits i) Budgeting Time, ii) Physical Conditions, iii) Reading Ability, iv) Note Taking, v) Learning Motivation, vii) Memory, viii) Taking Examination and ix) Health. The study habits of the individual cover mainly the reading habits, learning techniques, memory, time-schedule, physical conditions, examination, evaluation, etc.

Television viewing information blank: This information blank was developed by the investigators to ascertain the viewing duration of the subjects towards television. Subjects whose viewing duration was on and above the 
$75^{\text {th }}$ percentile ( 5 hours and above) on television viewing information blank were considered as heavy viewers and subjects whose viewing duration was on and below the $25^{\text {th }}$ percentile ( 2 hours and below) were considered as low viewers.

\section{Statistical Analysis:}

The data was subjected to statistical analysis by computing percentages, Mean, S.D. and test of significance.

Table 1: Signifirance of differences between the mean scores of Heavy and Low Television viewers on Study habits (N = 120 each)

\begin{tabular}{|c|c|c|c|c|c|c|}
\hline \multirow{2}{*}{ Areas } & \multicolumn{2}{|c|}{ Heavy TW. viewers } & \multicolumn{2}{|c|}{ Low TV. viewers } & \multirow{2}{*}{ 't' Value } & \multirow{2}{*}{ Results } \\
\cline { 2 - 5 } & $\bar{X}$ & SD & $\bar{X}$ & SD & & \\
\hline BT & 7.52 & 1.72 & 6.52 & 1.89 & 5 & $*$ \\
\hline PC & 7.17 & 1.41 & 8.64 & 1.33 & 10.5 & $*$ \\
\hline RA & 9.75 & 2.13 & 10.59 & 2.37 & 3.23 & $*$ \\
\hline IT & 4.61 & 1.01 & 4.20 & 1.07 & 3.15 & $*$ \\
\hline LWI & 9 & 1.63 & 9.91 & 1.56 & 4.55 & $*$ \\
\hline MI & 4.08 & 0.97 & 5.4 & 1.28 & 9.42 & $*$ \\
\hline TE & 12.29 & 2.11 & 13.22 & 2.49 & 3.32 & $*$ \\
\hline H & 3.64 & 1.05 & 4.25 & 0.93 & 6.1 & $*$ \\
\hline
\end{tabular}

+Significant at 0.01 level

Figure- I

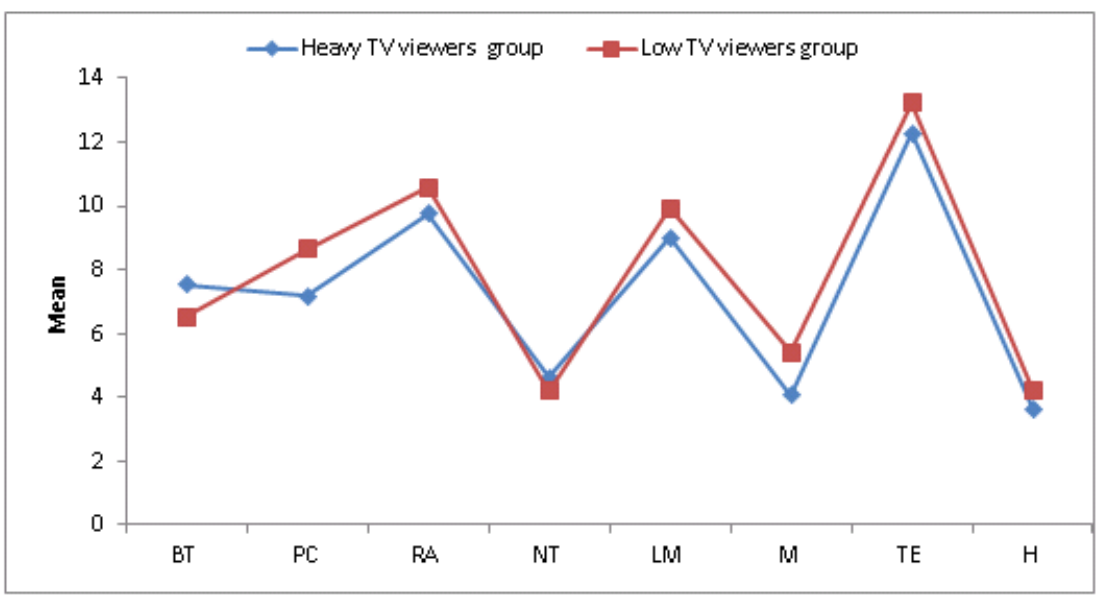

Index

BT: Budgeting Time

PC: Physical Conditions for Study

RA: Reading Ability

LM: Leaming Motivation

NT: Note Taking
M: Memory
TE: Taking Exarnination
$\mathrm{H}$ : Health 
Table 2: Significance of differences between the mean scores of Heavy TV viewers on study habits (Gender comparison $N=60$ each)

\begin{tabular}{|c|c|c|c|c|c|c|}
\hline \multirow{2}{*}{ Areas } & \multicolumn{2}{|c|}{$\begin{array}{l}\text { Heavy TV.viewers } \\
\text { Male grou甲 }\end{array}$} & \multicolumn{2}{|c|}{$\begin{array}{l}\text { Heavy TV. viewers } \\
\text { Female grou }\end{array}$} & \multirow{2}{*}{ 't' Value } & \multirow{2}{*}{ Results } \\
\hline & $\overline{\bar{X}}$ & SD & $\overline{\bar{X}}$ & SD & & \\
\hline$\overline{B T}$ & 7.01 & 1.75 & 8.03 & 1.55 & 3.4 & * \\
\hline$\overline{\mathrm{PC}}$ & 7.1 & 1.38 & 7.25 & 1.44 & 0.62 & (d) \\
\hline $\mathrm{RA}$ & 9.41 & 2.01 & 10.08 & 2.20 & 1.81 & (2) \\
\hline NT & 4.51 & 1.14 & 4.71 & 0.86 & 1.17 & (2) \\
\hline LM & 8.71 & 1.78 & 9.28 & 1.43 & 2.03 & 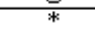 \\
\hline $\mathrm{M}$ & 4.03 & 0.68 & 4.13 & 1.19 & 0.62 & (2) \\
\hline $\mathrm{TE}$ & 12.88 & 2.15 & 11.7 & 1.90 & 3.27 & * \\
\hline $\mathrm{H}$ & 3.78 & 1.13 & 3.5 & 0.96 & 1.64 & (2) \\
\hline
\end{tabular}

Figure- II

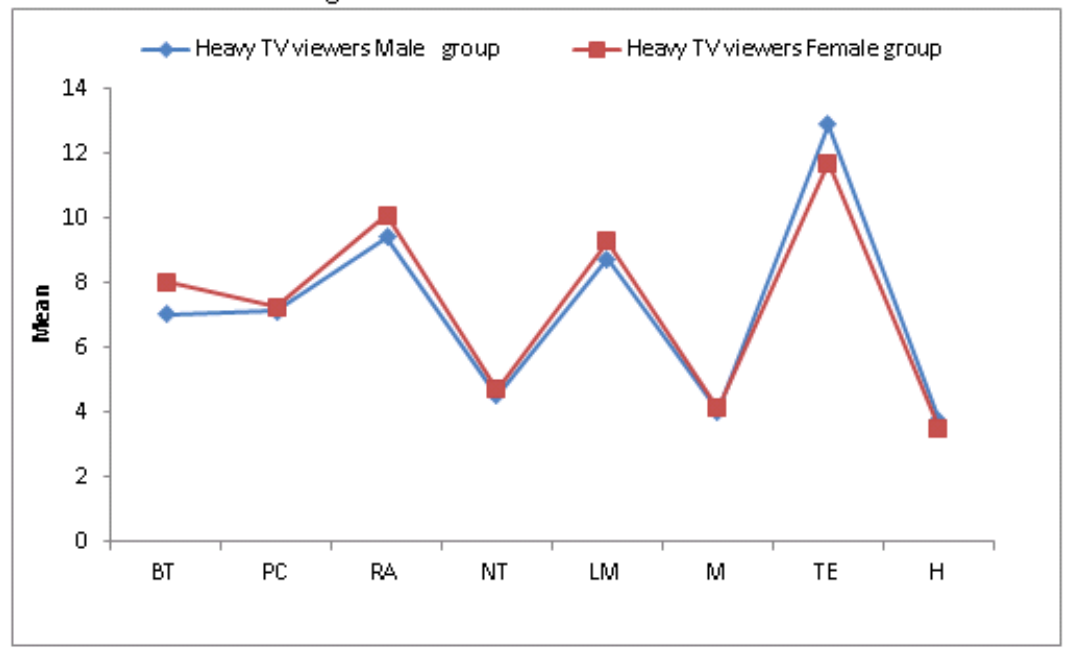

Inder

BT: Budzetrires Time

PC: Flyreical Coruditions for Stutr

FA: Readires Ability

HT: Note Tariris
LM: Learinite Motiration

M: Mamorr

TE: Takires Examination

$\mathrm{H}$ : Heatth 
Table 3: Significance of differences between the mean scores of Low TV vieuers on their study habits on the basis of gender (N $=60$ each)

\begin{tabular}{|c|c|c|c|c|c|c|}
\hline \multirow{2}{*}{ Areas } & \multicolumn{2}{|c|}{$\begin{array}{c}\text { Low TV. viewers Male } \\
\text { group }\end{array}$} & \multicolumn{2}{|c|}{$\begin{array}{l}\text { Low TV. viewers } \\
\text { Female group }\end{array}$} & \multirow{2}{*}{ 't' Vahue } & \multirow{2}{*}{ Results } \\
\hline & $\overline{\bar{X}}$ & SD & $\overline{\bar{X}}$ & SD & & \\
\hline BT & 6.81 & 1.65 & 6.23 & 2.07 & 1.75 & Q \\
\hline$\overline{\mathrm{PC}}$ & 8.56 & 1.26 & 8.71 & 1.41 & 0.68 & Q \\
\hline RA & 10.5 & 2.36 & 10.68 & 2.41 & 0.42 & Q \\
\hline HT & 4.26 & 0.86 & 4.15 & 1.25 & 0.64 & Q \\
\hline LM & 9.61 & 1.68 & 10.21 & 1.37 & 2.30 & (not) \\
\hline $\mathbf{M}$ & 5.13 & 1.28 & 5.66 & 1.27 & 2.65 & it \\
\hline $\mathrm{TE}$ & 13.65 & 2.69 & 12.8 & 2.21 & 1.93 & Q \\
\hline $\mathrm{H}$ & 4.25 & 1.05 & 4.26 & 0.79 & 0.07 & Q \\
\hline
\end{tabular}

Fgure III

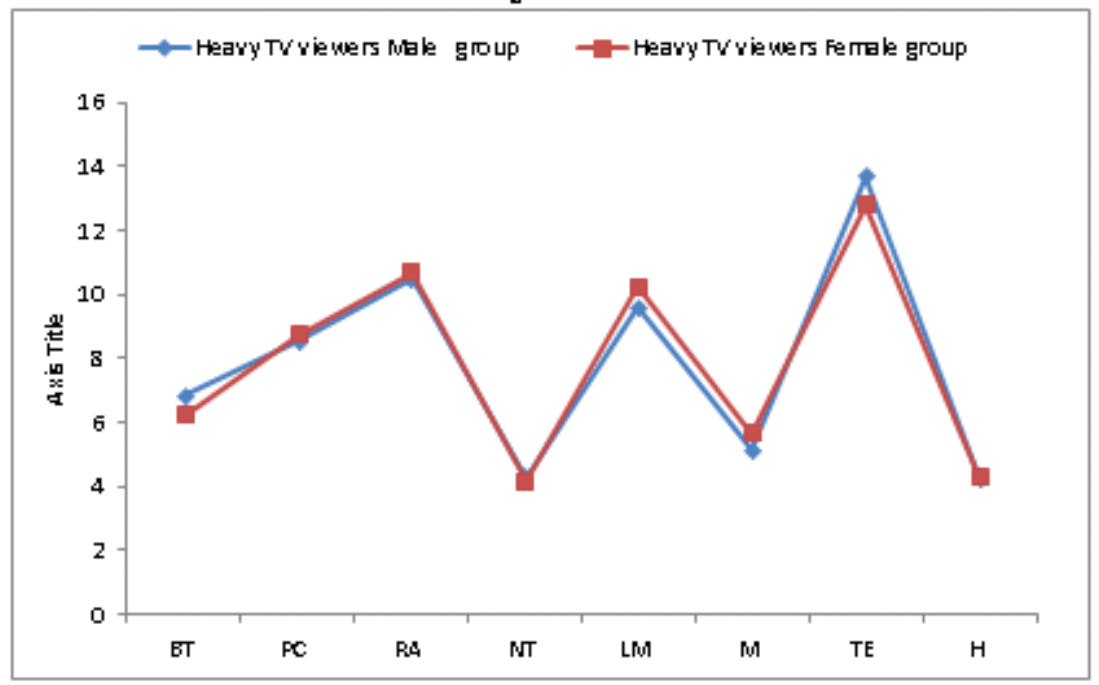


Table 3: Significance of differences between the mean scores of Low TV viewers on their study habits on the basis of gender ( $N=60$ each)

Significant at 0.01 level ** Significant at 0.05 level @ Not Significant

\begin{tabular}{|c|c|c|c|c|c|c|}
\hline \multirow[t]{2}{*}{ Areas } & \multicolumn{2}{|c|}{$\begin{array}{c}\text { Low TV. viewers Male } \\
\text { group }\end{array}$} & \multicolumn{2}{|c|}{$\begin{array}{l}\text { Low TV. viewers } \\
\text { Female grout }\end{array}$} & \multirow[t]{2}{*}{ 't' Value } & \multirow[t]{2}{*}{ Results } \\
\hline & $\overline{\bar{X}}$ & SD & $\bar{X}$ & SD & & \\
\hline$\overline{\mathrm{BT}}$ & 6.81 & 1.65 & 6.23 & 2.07 & 1.75 & (i) \\
\hline $\mathrm{PC}$ & 8.56 & 1.26 & 8.71 & 1.41 & 0.68 & (d) \\
\hline$\overline{\mathrm{RA}}$ & 10.5 & 2.36 & 10.68 & 2.41 & 0.42 & (d) \\
\hline NT & 4.26 & 0.86 & 4.15 & 1.25 & 0.64 & (i) \\
\hline$\overline{L M}$ & 9.61 & 1.68 & 10.21 & 1.37 & 2.30 & $* *$ \\
\hline $\mathrm{M}$ & 5.13 & 1.28 & 5.66 & 1.27 & 2.65 & $*$ \\
\hline $\mathrm{TE}$ & 13.65 & 2.69 & 12.8 & 2.21 & 1.93 & (d) \\
\hline $\mathrm{H}$ & 4.25 & 1.05 & 4.26 & 0.79 & 0.07 & (d) \\
\hline
\end{tabular}

Figure- III

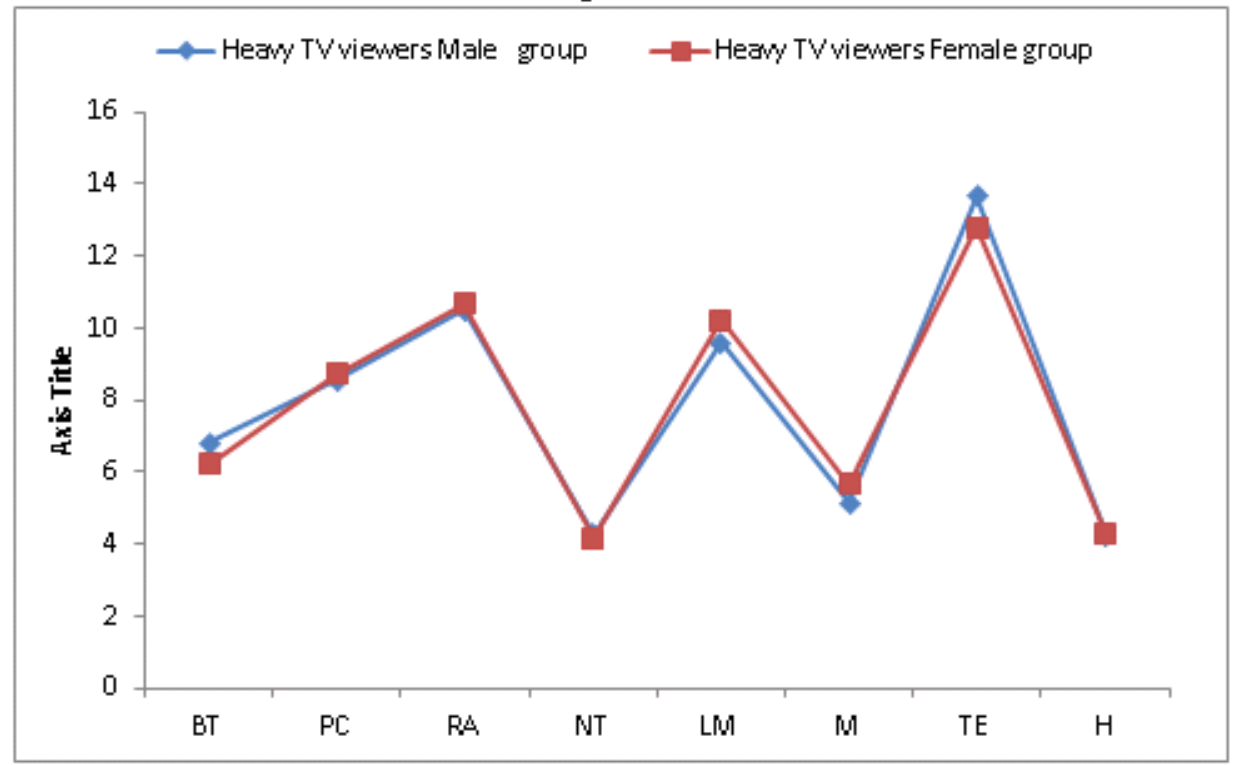

Index

BT: Budgeting Time

PC : Physical Conditions for Study

RA: Reading Ability

NT: Note Taking

LM: Leaming Motivation

M: Memory

TE: Taking Exarnination

H: Health 


\section{Analysis and Interpretation:}

A perusal of Table 1.00 (Fig. I) reveals the significant differences between the mean scores of heavy and low $\mathrm{TV}$ viewers on study habits in all the eight areas. The differences have been found to be significant at 0.01 level of confidence. From these results, it is revealed that the heavy TV viewers as compared to low TV viewers are seen to plan their time well in advance $(M=7.52, t=5.00)$; possess higher note taking ability $(M=4.61, t=3.15)$; whereas low TV viewers have been found higher in study habits with respect to physical conditions for study ( $\mathrm{M}=8.64, \mathrm{t}=10.5)$; reading ability $(\mathrm{M}=10.59, \mathrm{t}=3.23)$; learning motivation $(\mathrm{M}=9.91, \mathrm{t}=4.55)$; memory $(M=5.4, t=9.42)$; taking examination $(M=13.22, t=3.32)$; health $(4.25, t=6.1)$. The results further reveal that heavy TV viewers plan their studies on time and adjust their time according to their own needs. Since these subjects are heavily involved in TV viewing so they accordingly check out the programme of activities well in advance. Besides, it has also been found that heavy TV viewers manage their note taking habits in paraphrasing and summarizing their classroom notes in their own words. As against this, the low TV viewers have been found to prefer quit and clam style of working, they keep their place of study clean and illuminated. Low TV viewers have been observed to be careful to keep their things in ordered fashion. The table further reveals that low TV viewers have shown a good vocabulary, speed in reading and comprehension with regard to reading ability. They have also been found to have a good amount of learning motivation. The table further reveals that low TV viewers have been found to be good in memory and possess remembering skill for a longer period; they possess good study habits of taking examinations i.e. they prepare an outline and arrange the ideas properly, follow a logical pattern of presentation, use simple language and place headings and sub headings properly. Low TV viewers have also been seen in sound health condition which otherwise is considered as an essential postulate in achieving success in the examination.

The data has further been analyzed by way of computing 't' values between heavy TV viewers on the basis of gender in each of the eight areas on study habits. Table No. 2.00 (Fig. II) reveals that the two groups have been found significantly different from each other in three areas of study habits at 0.01 level. However, in five areas i.e. physical conditions, reading ability, note taking, memory and health, the difference between the mean scores failed to arrive at any level of significance. From these results, it is observed that heavy TV viewer male subjects $(M=12.18)$ as compared to heavy TV viewer female subjects $(M=11.17)$ have tendency towards study habits viz. taking examination $(\mathrm{t}=3.27$ ), where as heavy TV viewer female group of subjects has been found to have good tendency in budgeting time properly $(\mathrm{M}=8.03, \mathrm{t}=3.4)$ and learning motivation $(\mathrm{M}=9.28, \mathrm{t}=2.03)$. However, in rest of the five areas of study habits, the difference between the mean scores could not be established. This can be said gender does make any difference among heavy viewers in their study habits like: physical conditions, reading ability, note taking, memory and health.

To conclude, it is revealed that heavy TV viewer female subjects plan their time for studies properly, adjust the study periods and maintain record of all activities. This planning helps them to adjust other activities according to their own needs which help them to gain success. Female heavy TV viewers are also seen to have: good amount of learning motivation; desire to learn quickly and retention ability for a long time. But on the other hand, heavy TV viewer male subjects possess good study habits of taking examinations i.e. they arrange ideas properly and follow logical pattern. They prepare an outline and arrange the ideas properly, following a logical pattern of presentation, uses simple language and place headings and sub headings properly. In remaining areas of study habits both the groups have been found to be similar i.e. physical conditions, reading ability, memory, note taking, and health. So, it is concluded that heavy TV viewers (male and female group) more or less do not differentiate themselves in majority of the areas of study habits, The data on study habits has further been analyzed by way of computing ' $t$ ' values between low TV viewer male and female group of subjects on each of the eight areas of study habits. Table No.3.00 ( Fig. III) reveals that no significant differences between the mean scores of low TV viewer male and female subjects are observed except in two areas i.e. learning motivation and memory. In six, out of eight areas on study habits, the two groups have to be found similar. However, in rest of the areas i.e. learning motivation and memory, the two groups have been found significantly different from each other at 0.01 level. The other six areas of study habits i.e. budgeting time, physical conditions, reading ability, note taking, taking examination and health, the difference between the mean scores failed to arrive at any level 
of significance. From these results, it is revealed that low TV viewer female group of subjects as compared to low TV viewer male group of subjects has a tendency of good study habits in learning motivation ( $M=10.21$, $\mathrm{t}=2.30$ ), and memory $(5.66, \mathrm{t}=2.65)$. However, in rest of the areas of study habits i.e. budgeting time, physical conditions, reading ability, note preparation, taking examination and health, the differences between the mean scores could not be established. This can be said low TV viewers have more or less similar study habits. It can further be inferred that gender differences do not make any variation amongst the subjects in budgeting time, physical conditions, reading ability, note taking, taking examination and health like areas of study habits.

The results further reveals that low TV viewers have a good amount of learning motivation; are seen to have a desire to learn quickly and retaining of information for a long time. The table further reveals that low TV viewer female group of subjects' exhibit good habit in memorizing and remembering the facts for a longer period. In remaining areas of study habits both the groups under investigation. (Low TV viewer male and female subjects) have been found similar in budgeting time, physical conditions, reading ability, note taking, taking examination and health. It is revealed that low TV viewers male and female group of subjects are more or less similar in majority of the areas of study habits. The results are in agreement with the findings of the earlier researchers: ( Brain, and Stephanie, 2007; Nary, 2004; Rideout, 2003; Voort, 2001; Koolstra and Voort, 1996; Gupta, et.al., 1994; Susan, 1988).

\section{References:}

Anderson, D. R. et al. (2001): Early childhood television viewing and adolescent behavior: The recon tact study. Monographs of the Society for Research in Child Development. Vol. 66 No.1, Pp. 1-147.

Anderson, D. R et al. (2001): Early Childhood television viewing and adolescent behavior. Monographs of the Society for Research in Child Development. Vol. 66 No.1, P. 264.

Arnett, J. J. (1995). Adolescents' uses of media for self-socialization. Journal of Youth and Adolescence, Vol. 24: Pp. 519-533.

Beentjes, B. J. (1988): Television's impact on children's reading skills: A review of research. Reading Research Quarterly, Vol. 23, Pp. 389-413.

Boehnke, K., Munch, T \& Hoffmann, D. (2002): Development through media use? A German study on the use of radio in adolescence. International Journal of Behavioral Development. Vol. 26, Pp. 193-201.

Bushan, C. (1992): Educational Communication by Television. Bharatia Skikshan. Vol.2, No.8. Bombay: S. Cmela Mergh.

Caldas, S. J. and Bankston, C. (1999). Black and white TV: Race, television viewing, and academic achievement. Sociological Spectrum, Vol. 19 (1): Pp 39-62.

Eggerment \& Steven (2006): There is no meaningful relationship between exposure to television and symptoms of Attention-Deficit Hyperactivity Disorder. Pediatrics, Vol. 117: Pp; 665-672.

Koolstra, C. (1999): Longitudinal effects of television on children's leisure-time reading: A test of three explanatory models. Human Communication Research, Vol. 23, Pp. 4-35.

Kubey and Csikszentmihaly (1990): Television use in everyday life: Coping with unstructured time. Journal of Communication. Vol.36, Pp. 108-123.

Miller (2007): Extensive Television Viewing and the Development of Attention and Learning Difficulties during Adolescence. Arch Pediatr Adolesc Med; Vol. 161: pp, 480-486. 
Moses, A M. (2008): Impact of viewing on young children's literacy development. Journal of Early Childhood Literacy, Vol. 8 No. 1, Pp. 67-102.

Mrunalini, T. (1997): Education and Electronic Media. New Delhi: APH Publishing Corporation.

Nary, S. (2004): Exploring Pathways from Television Viewing to Academic Achievement in School Age Children. The Journal of Genetic Psychology Issue: Vol. 165, No. 4, Pp. 367 - 382.

Parker. (1961): The effects of television on public library circulation. Public Opinion Quarterly. Vol. 27, Pp. $578-587$.

Razel, M. and Van Den Broek (2001): The complex model of television viewing and educational achievement. Journal of educational research. Vol. 94 No.6, Pp. 371-380.

Roberts, D. F. (2000). Media and youth: Access, exposure, and privatization. Journal of Adolescent Health, Vol. 27(2): Pp. 8-14.

Syed, N.A (2010) Influence of TV watching on study habits and academic achievement of secondary school students in relation to socio-economic status. Unpub. M.Phil. dissertation, University of Kashmir.

Trividi, H. (1991). Mass Media and News Horizons Impact of Television and Video on Urban Milleiu, New Delhi: Concept Publishing Company.

Van Den Broek, P. (2001): The role of television viewing in the development of reading comprehension (Report No. CS-014521). Washington, DC: Office of Educational Research and Improvement. (ERIC Document Reproductive Service No. ED458552).

Van Der Voort, T. H. A. (2001): Television's impact on children's leisure-time reading and reading skills. In Literacy and motivation. Reading and engagement in individuals and groups. Eds. Verhoeven, L., and Snow, C.E. Mahwah, New Jersey and London: Lawrence Erlbaum Associates, Pp. 95-119.

Williams, P.A et al. (1986): The Impact of Leisure-Time Television on School Learning. American Educational Research Journal. Vol. 19, No. 1. Pp. 19-50. 
This academic article was published by The International Institute for Science, Technology and Education (IISTE). The IISTE is a pioneer in the Open Access Publishing service based in the U.S. and Europe. The aim of the institute is Accelerating Global Knowledge Sharing.

More information about the publisher can be found in the IISTE's homepage: http://www.iiste.org

The IISTE is currently hosting more than 30 peer-reviewed academic journals and collaborating with academic institutions around the world. Prospective authors of IISTE journals can find the submission instruction on the following page: http://www.iiste.org/Journals/

The IISTE editorial team promises to the review and publish all the qualified submissions in a fast manner. All the journals articles are available online to the readers all over the world without financial, legal, or technical barriers other than those inseparable from gaining access to the internet itself. Printed version of the journals is also available upon request of readers and authors.

\section{IISTE Knowledge Sharing Partners}

EBSCO, Index Copernicus, Ulrich's Periodicals Directory, JournalTOCS, PKP Open Archives Harvester, Bielefeld Academic Search Engine, Elektronische Zeitschriftenbibliothek EZB, Open J-Gate, OCLC WorldCat, Universe Digtial Library, NewJour, Google Scholar

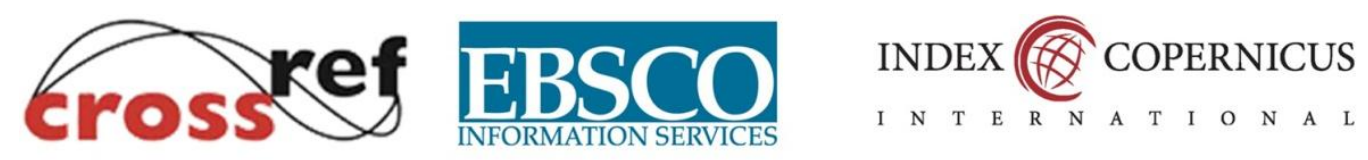

\section{Ounachener}

JournalTOCs

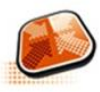

PKP | PUBLIC KNOWLEDGE PROJECT
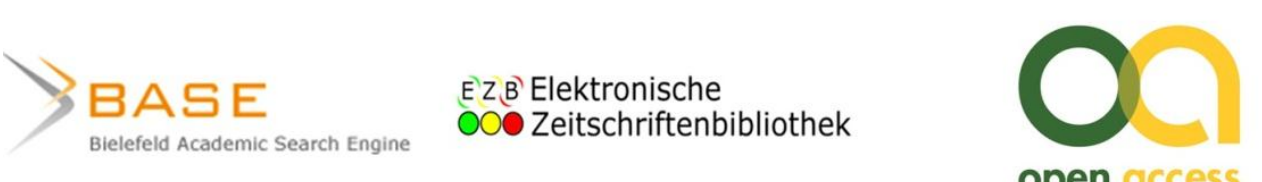

open access

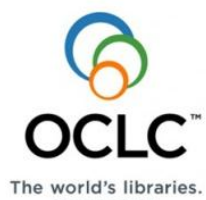

Connected.
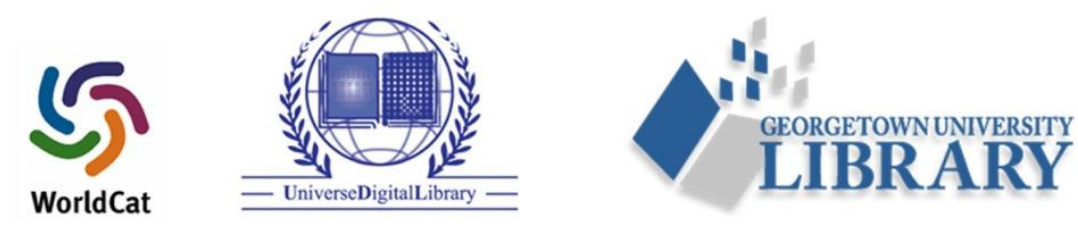